\title{
ANALISIS GERAK MOTORIK KASAR PADA PERMAINAN LOMPAT TALI TERHADAP PRESTASI SISWA PUTRA DALAM LOMPAT JAUH PADA KELAS VIII SMP NEGERI 2 PALIBELO
}

\begin{abstract}
Shutan Arie Shandi*
Abstrak : Penelitian ini bertujuan untuk mengetahui apakah ada pengaruh gerak motorik kasar pada permainan lompat tali terhadap prestasi siswa putra dalam lompat jauh pada kelas VIII SMP Negeri 2 Palibelo Kabupaten Bima. Penelitian ini dilakukan di SMP Negeri 2 Palibelo Kabupaten Bima pada semua siswa putra kelas VIII dengan jumlah populasi 56 orang siswa putra. Sampel yang di ambil adalah seluruh populasi yang ada yaitu sebanyak 56 orang siswa putra. Adapun tehnik pengumpulan data adalah menggunakan observasi, dokumentasi dan tes perbuatan. Untuk mengetahui pengaruh gerak motorik kesar pada permainan lompat tali terhadap prestasi siswa putra dalam lompat jauh diperlukan sarana dan prasana yang lengkap dan baik.

Tekhnik analisis data yang digunakan adalah rumus statistik regresi linear sederhana, diperoleh persamaan $\mathrm{Y}=\mathrm{a}+\mathrm{b}(47,5090,311), \mathrm{a}=47,509$ artinya bersamanya nilai konstanta variabel prestasi lompat jauh (Y) tampa ada pengaruh dari fariabel gerak motorik kasar pada permainan lompat tali $(\mathrm{X})$ sedangkan $\mathrm{b}=$ 0,311 artinya angka ini menunjukan bahwa setiap penurunan atau peningkatan sebesar satu satuan jenjang kriteria variabel gerak motorik kasar pada permainan lompat tali (X) akan memberikan pengaruh peningkatan atau penurunan terhadap penurunan variabel prestasi lompat jauh $(\mathrm{Y})$ sebesar 0,31 satuan jenjang kriteria, sehingga semakin cepat gerak motorik kasar pada permaianan lompat tali seseorang (siswa), maka semakin tinggi lompatannya dalam melakukan lompat jauh. maka hipotesis nol (Ho) ditolak dan hipotesis alternatif (Ha) diterima. Dengan KP kontribusi atau pengaruh sebesar 49\%. Dengan demikian dapat disimpulkan bahwa ada pengaruh gerak motorik kasar pada permainan lompat tali terhadap prestasi siswa putra dalam lompat jauh pada kelas VIII SMP Negeri 2 Palibelo Kabupaten Bima tahun pelajaran 2012/2013.
\end{abstract}

Kata kunci: Motorik Kasar, Lompat Jauh

\section{PENDAHULUAN}

Permainan lompat tali secara fisik akan menjadikan anak lebih kuat dan tangkas. Belum lagi manfaat emosional, intelektual dan sosial yang akan berkembang dalam diri anak tersebut. Lompat tali atau "main karet" pernah popular dikalangan anak angkatan 70-an hingga 80-an. Permainan lompat tali ini pernah menjadi faforit saat "keluar main" di sekolah dan setelah mandi sore di rumah. Cara bermainnya masih tetap sama, bisa dilakukan perorangan ataupun berkelompok. Jika hanya bermain seorang diri biasanya anak akan mengikatkan tali pada tiang, batang pohon atau pada apapun yang memungkinkan, lalu melompatinya.

Permainan secara soliter bisa juga dengan cara skipping yaitu memegang kedua ujung tali kemudian mengayunkannya melewati kepala dan kaki sambil melompatinya. Seiring dengan perkembangan ilmu pengetahuan, bidang olahraga mengalami perkembangan dalam pembangunan untuk mencetak atlet yang berprestasi.

\footnotetext{
*Penulis adalah Staf Edukatif Prodi Penjaskesrek STKIP Taman Siswa Bima
} 
Shutan Arie Shandi : Analisis Gerak Motorik Kasar Pada Permainan Lompat Tali Terhadap Prestasi Siswa Putra Dalam Lompat Jauh Pada Kelas VIII SMP Negeri 2 Palibelo

Dalam hal ini diperlukan suatu usaha-usaha ilmiah dan memerlukan suatu analisis gerak manusia sesuai dengan ilmu gerak tubuh. Kegiatan olahraga mempunyai tujuan untuk membina dan meningkatkan kesegaran jasmani dan rohani secara ilmiah. Hal ini termuat dalam Undang-Undang Nomor 3 Tahun 2005, yang berbunyi sebagai berikut: "Sistem keolahragaan nasional adalah keseluruhan aspek keolahragaan yang saling terkait secara terencana, sistimatis, terpadu, dan berkelanjutan sebagai satu kesatuan yang meliputi pengaturan, pendidikan, pelatihan, pengelolaan, pembinaan, pengembangan, dan pengawasan untuk mencapai tujuan keolahragaan nasional", (Undang-Undang Nomor 3 Tahun 2005 tentang Sistem Keolahragaan Nasional).

Memasyarakatkan olahraga dan mengolahragakan masyarakat untuk menggugah kesadaran bangsa akan pentingnya nilai olahraga dalam kehidupan berbangsa dan Negara. Diantara sekian cabang olahraga yang ada di dunia, atletik merupakan cabang olahraga yang tertua, karena itu juga disebut sebagai induk dari semua cabang olahraga (the mother off sport). Dikatakan sebagai induk dari semua cabang olahraga karena gerakan-gerakan dasar dari atletik seperti jalan, lari, lempar dan lompat sebagian besar digunakan pada cabang olahraga lain.

Dari nomor-nomor atletik yang diperlombakan seperti jalan, lari, lempar dan lompat, penulis memilih nomor lompat, yaitu lompat jauh sebagai bahan penelitian. Jika diperhatikan prestasi cabang lompat jauh Indonesia masih ketinggalan dengan Negara lain, jangankan di tingkat dunia, di tingkat Asia Tenggara saja belum bias berbicara banyak. Selain itu juga sangat sedikit orang yang mau menekuni nomor lompat jauh dengan sungguh-sungguh. Maka dari itu selama ini kita belum mempunyai atlet lompat jauh yang mampu berprestasi tinggi. Untuk mendapat prestasi yang tinggi di bidang olahraga khususnya nomor lompat jauh memang tidak mudah. Latihan yang teratur dan disiplin yang tinggi sangat diperlukan.

Atlet pelompat jauh mempunyai tujuan untuk melompat kedepan sejauh-jauhnya. Untuk mencapai jarak lompatan yang jauh, harus diperhatikan secara baik unsur pokok yang diperlukan untuk melompat. Adapun yang diperlukan unsur-unsur yang diketahui dalam nomor lompat jauh adalah dapat membangun atau membangkitkan atau memindahkan gaya momentum yang sebesar-besarnya, harus dapat menggunakan atau memindahkan gaya momentun yang sudah dibangun dari yang horizontal kearah vertikal, harus dapat mempersatukan gaya-gaya tersebut dengan tenaga badan pada saat menolak, harus dapat mempergunakan titik berat badan seefisien mungkin.

Mengingat pentingnya perhatian sekolah terhadap siswa berprestasi, maka fenomena ini perlu diteliti, dikaji dan ditelaah. Lalu, tindakan-tindakan apa saja yang telah dilakukan oleh pihak sekolah dalam mendukung siswa yang berprestasi dalam bidang olahraga.

Beranjak dari penjelasan dengan permasalahan yang telah dikemukakan, sehingga perlu adanya pembuktian secara ilmiah dengan melalui penelitian. Berdasarkan latarbelakang di atas, maka peneliti tertarik untuk mengangkat dan melakukan penelitian dengan judul: Analisis Gerak Motorik Kasar Pada Permainan Lompat Tali Terhadap Prestasi Siswa Putra Dalam Lompat Jauh Pada Kelas VIII SMP Negeri 2 Palibelo Kabupaten Bima.

\section{Lompat Tali}

Lompat tali adalah gerakan melompat yang dilakukan secara soliter bisa juga dengan cara skipping yaitu memegang kedua ujung tali kemudian mengayunkannya melewati kepala dan kaki sambil melompatinya berulang-ulang sehingga sampai memperoleh hasil yang di inginkan. Permianan lompat tali sebagai penunjang sarana dan prasarana untuk menambah pembentukan atau agar lebih terstimulasinya otot-otot bagian tubuh manusia atau individu tersebut. Mengawali latihan lompatan untuk menstimulasikan otot-otot pada bagian tubuh yang dapat meningkatkan kekuatan dan kecepatan serta akan menambah keterampilan pada 
saat melakukan lompatan yang lebih dinamis. Permainan lompat tali adalah salah satu cara yang praktis yang bisa dilakukan untuk mengawali latihan serta guna pembetukan otot-otot pada bagian tubuh tertentu.

\section{Motorik Kasar}

Gerak motorik kasar adalah pembentukan otot-otot pada bagian tubuh tertentu dengan adanya upaya yang dilakukan oleh manusia atau individu tersebut sehingga terjadinya pembentukan otot-otot pada lengan, bahu, paha, betis dan lainlain.

Pada dasarnya seorang individu telah tersimulasi gerak motoriknya yaitu pada saat manusia atau individu itu mulai melakukan gerakan-gerakan kecil dan ringan seperti merangkak, berdiri, berjalan, hingga berlari. Dalam hal ini, pembentukan otot tidak terjadi dengan sendirinya, tetapi melainkan dengan suatu usaha melakukan suatu gerakan yang berfariasi ringan ataupun berat seperti, pus up, pull up, beck up. Untuk melatih tingkatan kecepatan dalam pembentukan motorik pada tubuh khususnya pada betis dan paha adalah dengan melakukan lompat tali skipping yaitu memegang kedua ujung tali dan memutar melewati kepala sambil melompatinya.

Kadar karakteristik fisik dan emosional setiap cabang olahraga berbeda-beda. Di dalam lompat jauh tentunya tidak terlepas dari faktor yang mendukung yaitu kekuatan otot kaki. Untuk lebih jelasnya "Kekuatan otot yang juga disebut dengan Strenght adalah menggambarkan kotraksi maksimal yang di hasilkan oleh otot atau sekelompok otot yang nantinya menghasilkan tenaga manusia untuk bergerak," (Rusdiyanto, 1988:36).

Dalam melaksanakan olahraga, kekuatan otot faktor penentu untuk mencapai prestasi yang maksimal. Begitu juga dengan olahraga lompat jauh kekuatan otot kaki merupakan yang utama, khususnya dalam prestasi lompat jauh. Untuk memperoleh hasil yang lebih baik dalam aktivitas olahraga khususnya lompat jauh banyak faktorfaktor yang mendukung seperti kelincahan, kecepatan, keseimbangan, koordinasi, ketahanan akan tetapi harus di kombinasikan dengan faktor kekuatan agar memperoleh hasil yang lebih baik dan dengan kekuatan juga dapat memperoleh hasil yang maksimal. (Harsono, 1988:77).

\section{Lompat Jauh}

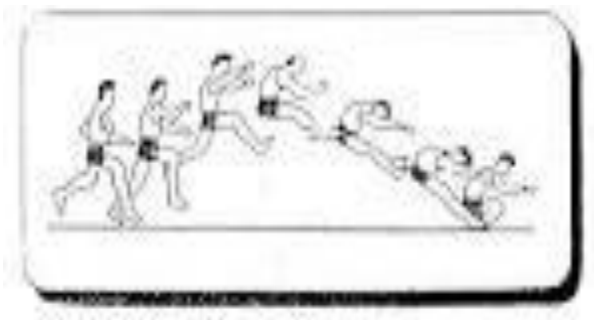

Teknik Lompat Jauh

Lompat jauh adalah atletik (lintasan dan lapangan) peristiwa di mana atlet menggabungkan kecepatan, kekuatan dan ketangkasan dalam upaya untuk melompat sejauh dari take-off point mungkin.

Dalam olahraga nomor lompat ini memerlukan suatu keterampilan dan kecekatan untuk bisa melompat atau melakukan suatu tolakan yang sangat kuat agar dapat mencapai lompatan sejauh yang di inginkan, maka atlet harus semaksiamal mungkin dapat berlatih melakukan lompatan sesering mungkin dan dapat 
Shutan Arie Shandi : Analisis Gerak Motorik Kasar Pada Permainan Lompat Tali Terhadap Prestasi Siswa Putra Dalam Lompat Jauh Pada Kelas VIII SMP Negeri 2 Palibelo

menciptakan suatu irama langkah kaki untuk mencapai suatu tujuan untuk dapat melompat dan menolak pada saat melakukan lompatan pada papan take off.

Lompat jauh merupakan salah satu nomor lompat dari cabang atletik. Tujuan dari lompat jauh adalah melompat dengan tolakan sejauh-jaunya dengan satu kali lompatan. Keterampilan olahraga lompat jauh hampir sama dengan nomor lari jarak pendek, karena kesamaan dari otot-otot yang di gunakan seperti otot kaki dan otot perut. Oleh karena adanya beberapa atlet lari jarak pendek yang sukses di nomor lompat jauh seperti sprinter dari Amerika Serikat di tahun 80 sampai 90-an Yitu Carl Lewis (Sahadi Anwarudin, S.Pd, 2011:27).

METODE

Penelitian yang dilakukan adalah penelitian deskriptif. Penelitian deskriptif bertujuan untuk membuat, menggambarkan secara sistematis faktual dan akurat mengenai faktor-faktor dan sifat-sifat populasi atau daerah tertentu dan mencari korelasi gerak motorik kasar pada permainan lompat tali terhadap prestasi siswa putra dalam lompat jauh pada kelas VIII SMP Negeri 2 Palibelo Kabupaten Bima, (Suryabrata, dkk, 2000).

Pendekatan penelitian ini menggunakan pendekatan kualitatif (pendekata non eksperimen), karena penelitian ini hanya mengumpulkan data tanpa mengadakan perlakuan terhadap variabel-variabel atau dalam pengumpulan data yang objektif dan dalam memecahkan masalah di lapangan, (Margono, 2001).

Menurut Arikunto, (1988:120) populasi adalah keseluruhan subjek dari penelitian. Sesuai dengan pendapat tersebut, maka populasi penelitian ini adalah siswa putra dikelas VIII pada SMP Negeri 2 Palibelo Kabupaten Bima tahun pelajaran 2012/2013 yang berjumlah 95 orang.

Tabel Populasi

\begin{tabular}{ccccc}
\hline No. & Kelas & L/P & Jumlah Siswa & Keterangan \\
\hline 1 & VIII A & L/P & 32 & - \\
\hline 2 & VIII B & L/P & 31 & - \\
\hline 3 & VIII C & L/P & 32 & - \\
\hline & Jumlah & & 95 & - \\
\hline
\end{tabular}

Dalam penelitian ini peneliti mengambil sampel 56\% dari populasi yang digunakan, jadi jumlah sampelnya sebanyak 56 orang dan sampel tersebut diambil secara proporsif sistematis random sampling dengan cara keseluruhan siswa putra kelas VIII SMP Negeri 2 Palibelo Kabupaten Bima tahun pelajaran 2012/213 di kelas VIIIa, VIIIb, dan VIIIc yang berjumlah 56\%-nya yaitu 56 orang siswa putra.

Table Data Jumlah Sampel

\begin{tabular}{cccc}
\hline No. & Kelas & Sample Siswa Putra & Keterangan \\
\hline 1 & VIII A & 22 & - \\
\hline 2 & VIII B & 12 & - \\
\hline 3 & VIII C & 22 & - \\
\hline Jumlah & 56 & - \\
\hline
\end{tabular}


Teknik ini digunakan untuk mengumpulkan data tentang adanya hubungan antara gerak motorik kasar dengan permainan lompat tali secara bersamaan dengan prestasi lompat jauh pada siswa putra kelas VIII SMP Negeri 2 Palibelo Kabupaten Bima tahun pelajaran 2012/2013.

Untuk teknik analisis data ini menggunakan teknik statistik korelasi product moment dan analisis regresi dengan taraf signifikan 5\%. Adapun untuk memudahkan dalam menganalisis data dari hasil pengukuran motorik kasar, lompat tali dan prestasi lompat jauh, maka diperlukan teknik analisis statistik sebagai berikut:

1. T-Skor

Hasil perhitungan data tidak langsung dibuat perhitungan karena diperoleh satuan ukur yang berbeda oleh karena itu semua data di transformasikan dalam bentuk standar T-Skor yang rumusnya seperti disebutkan oleh, (Sutrisno Hadi, 1984:75), yaitu:

Keterangan:

$$
T-S k o r=50 \pm \frac{X-\bar{X}}{S D} \times 10
$$

$$
\begin{array}{ll}
\boldsymbol{X} & =\mathrm{T}-\text { Skor kasar dari masing-masing variabel } \\
\overline{\boldsymbol{X}} & =\text { Maen (rata-rata) } \\
\boldsymbol{S D} & =\text { Standart deviasi }
\end{array}
$$

Langkah-langkah menghitung T-Skor adalah:

- Menghitung mean

- Menghitung standart deviasi

- Menghitung skor

2. Korelasi Product Moment

Dalam menghitung koefisien yaitu mengetahui tingkat hubungan masingmasing variabel bebas yaitu motorik kasar $\left(X_{1}\right)$ dan lompat tali $\left(X_{2}\right)$ dengan variabel terikat yaitu prestasi lompat jauh $(Y)$ memakai teknik statistik korelasi product moment disebutkan oleh Bambang Tahan Sungkono, (1985:33).

Keterangan:

$$
r x y=\frac{\sum X Y-\frac{\left(\sum X\right)\left(\sum Y\right)}{N}}{\sqrt{\left\{\sum X^{2}-\left(\frac{\sum X}{N}\right)^{2}\right\}\left\{\sum X^{2}-\left(\frac{\sum X}{N}\right)^{2}\right\}}}
$$

$$
\begin{array}{lc}
\boldsymbol{R x y} & \begin{array}{c}
\text { Koefisien korelasi antara variabel bebas dengan } \\
\text { variabel terikat. }
\end{array} \\
\boldsymbol{N} & \text { = Jumlah kasus (subjek) } \\
\boldsymbol{X Y} & =\text { Jumlah perkalian setiap kasus variabel } \\
\sum \boldsymbol{X} \boldsymbol{Y} & =\text { Jumlah } \mathrm{t} \text {-skor dari variabel bebas } \\
\sum \boldsymbol{Y} & =\text { Jumlah } \text { - }- \text {-skor dari variabel terikat } \\
\left(\sum \boldsymbol{X}\right)^{2} & =\text { Jumlah kuadrat dari variabel bebas } \\
\left(\sum \boldsymbol{Y}\right)^{2} & \text { = Jumlah dari variabel terikat }
\end{array}
$$

3. Analisis Regresi Ganda

Untuk menghitung besarnya koefisien korelasi antara gerak motorik kasar dan kecepatan lompat tali $\left(X_{2}\right)$ secara serentak dengan satu variabel terikat yaitu prestasi lompat jauh $(Y)$ digunakan teknik statistik analisis regresi ganda dengan rumus seperti yang dikemukakan oleh Sutrisno Hadi, (1992:25), yaitu: 
Shutan Arie Shandi : Analisis Gerak Motorik Kasar Pada Permainan Lompat Tali Terhadap Prestasi Siswa Putra Dalam Lompat Jauh Pada Kelas VIII SMP Negeri 2 Palibelo

Keterangan:

$$
\operatorname{Ry}(1,2)=\sqrt{\frac{a_{1} \cdot \sum X_{1 . Y}+a_{2} \sum X_{2} \cdot Y}{\sum Y^{2}}}
$$

4. Analisis Regresi

$$
\begin{array}{lc}
\boldsymbol{R y}(\mathbf{1 , 2}) & =\begin{array}{c}
\text { Koefisien korelasi antara variabel } X_{1} \text { dan } X_{2} \\
\text { dengan variabel } Y
\end{array} \\
\boldsymbol{a}_{1} & =\text { Koefisien predicator } X_{1} \\
\boldsymbol{a}_{2} & =\text { Koefisien predicator } X_{2} \\
\sum \boldsymbol{Y}^{\mathbf{2}} & \quad=\text { Jumlah variabel variabel } Y \text { dikudratkan } \\
\sum \boldsymbol{X 1 . Y} & =\text { Jumlah variabel } X_{1} \text { dikalaikan } Y \\
\sum \boldsymbol{X} \mathbf{2} . \boldsymbol{Y} & =\text { Jumlah variabel } X_{2} \text { dikalaikan } Y
\end{array}
$$

Untuk menghitung analisis regresi menurut Sutrisno Hadi, (1992:25), menggunakan rumus sebagai berikut:

$$
\text { Freg }=\frac{R^{2}(N-M-!)}{M\left(1-R^{2}\right)}
$$

5. Menghitung Bobot Sumbangan Relatif (SR\%) dan Bobot Sumbangan Efektif (SE\%).

Untuk menghitung bobot sumbangan relatif $(S R \%)$ dan sumbangan efektif (SE\%) menggunakan rumus seperti yang disebutkan oleh Bambang Tahan Sungkono, (1985:21), sebagai berikut:

a) Bobot Sumbangan Relatif

b) Bobot Sumbangan Efektif

$$
\begin{array}{r}
S R \% X 1=\frac{\sum X_{1 . Y}}{J K} \times 100 \% \\
S E \% X 2=\frac{\sum X_{2 . Y}}{J K} \times 100 \%
\end{array}
$$

$$
\begin{aligned}
& S R \% X_{1}=S R \% X_{1} R^{2} \\
& S R \% X_{2}=S R \% X_{2} R^{2}
\end{aligned}
$$

6. Kriteria Penolakan dan Penerimaan Hipotesis

Dalam penelitian ini hipotesis yang diajukan adalah hipotesis alternatif dan hipotesis kerja $\mathrm{(Ha}$ ) yang menyatakan bahwa ada hubungan antara motorik kasar dengan prestasi lompat jauh $(Y)$, ada hubungan antara kecepatan lompat tali $\left(X_{2}\right)$ dengan prestasi lompat jauh $(Y)$ dan ada hubungan antara motorik kasar $\left(X_{1}\right)$ dan kecepatan lompat tali $\left(X_{2}\right)$ dengan pretasi lompat jauh $(Y)$.

Kriteria penolakan dan penerimaan hipotesis dalam penelitian ini adalah apabila hipotesis alternatif $(\mathrm{Ha})$ diterima, maka hipotesis nihil $(\mathrm{Ho})$ ditolak dan demikian juga sebaliknya, apabila hipotesis alternatif ditolak, maka hipotesis nihil diterima.Untuk korelasi antara dua variabel pada taraf signifikan 5\% hipotesis alternatif diterima dan hipotesis nihil ditolak bila $F$ dihitung lebih besar atau sama dengan $F$ tabel, maka hipotesis alternatif diterima dan apabila $F$ dihitung lebih kecil dari $F$ tabel maka hipotesis nihil ditolak.

Taraf signifikan untuk korelasi antara dua variabel ditetapkan 5\% artinya apabila hipotesis alternatif diterima $95 \%$ ada hubungan positif antara keseluruhan dari variabel bebas dan terikat. Sedangkan untuk taraf signifikan analisis regresi ganda ditetapkan 5\% artinya apabila hipotesis alternatif diterima maka 95\% ada hubungan positif antara keseluruhan dari variabel bebas dan terikat. 
Jurnal Ilmu Keolahragaan Vol. 17 (2), Juli-Desember 2018: 46 - 53

\section{HASIL}

Hasil analisis data menggunakan rumus statistik regreasi linear sederhana, diperoleh persamaan $\mathrm{Y}=\mathrm{a}+\mathrm{b}(47,509+0,311), \mathrm{a}=47,509$ artinya bersamanya nilai konstanta variabel prestasi lompat jauh (Y) tampa ada pengaruh dari fariabel gerak motorik kasar pada permainan lompat tali $(\mathrm{X})$ sedangkan $\mathrm{b}=0,311$ artinya angka ini menunjukan bahwa setiap penurunan atau peningkatan sebesar satu satuan jenjang kriteria variabel gerak motorik kasar pada permainan lompat tali (X) akan memberikan pengaruh peningkatan atau penurunan terhadap penurunan variabel prestasi lompat jauh $(\mathrm{Y})$ sebesar 0,31 satuan jenjang kriteria, sehingga semakin cepat gerak motorik kasar pada permaianan lompat tali seseorang (siswa), maka semakin tinggi lompatannya dalam melakukan lompat jauh.

Sebaliknya semakin lambat atau kurangnya cepat gerak motorik kasar pada permainan lompat tali seseorang (siswa), maka semakin rendah lompatanya dalam melakuka lompat jauh. Untuk mengetahui hubungan variabel yang ada yaitu pengaruh gerak motorik kasar pada permainan lompat tali dengan prestasi lompat jauh, maka dilakukanya analisis data menggunakan rumus korelasi. Berdasarkan hasil analisis tersebut, koefisien korelasi 0,310 . Hasil tersebut di konsultsikan dengan tabel pada taraf signifikan 50\% dengan $\mathrm{N}=56$ yang menunjukan $0,260(0,310>0,26)$ artinya ada pengaruh gerak motorik kasar pada permainan lompat tali terhadap prestasi siswa putra dalam lompat jauh pada kelas VIII SMP Negeri 2 Palibelo Kabupaten Bima.

\section{PEMBAHASAN}

Meskipu dalam mencapai kecepatan lompat tali dalam melakukan lompat jauh banyak faktor mempengaruhinya, namun faktor gerak motorik kasar dapat mempengaruhi jarak lompatanya melakukan lompat jauh. Dengan demikian orang (siswa) yang lompatannya cepat ternyata lebih jauh lompatanya dalam melakukan lompat jauh dibandingkan dengan orang (siswa) yang lompatannya kurang cepat lebih pendek lompatanya dalam melakukan lompat jauh. Unsur-unsur yang berpengaruh terhadap kemampuan seseorang (siswa) dalam melakukan lompat jauh pada dasarnya sama dengan unsure-unsur yang terletak pada nomor lompat yang lain, meliputi : daya ledak, kekuatan, kelincahan, kelentukan, koordinasi, keseimbangan dan lain-lain.

Tamsir Riadi, (1985 : 95) dan Aip Syarifuddin, (1985) menjelaskan bahwa unsurunsur pokok dalam lompat jauh sebagai berikut : 1)Harus dapat membangkitkan daya momentum yang sebesar-besarnya., 2) Harus dapat memindahkan momentum yang horizontal ke vertical., 3) Harus dapat mempersatukan paduan gaya tersebut dengan tenaga badan pada saat melakukan tolakan., 4) Harus dapat menggunakan titik berat badan seefisien mungkin

Tetapi dalam hal ini penulis hanya meneliti sejauh mana pengaruh kecepatan lompat tali terhadap prestasi lompat jauh, dari hasil peneliti seperti yang telah diuraikan diatas terbukti bahwa kecepatan lompat tali dapat mempengaruhi prestasi lompat jauh.

\section{KESIMPULAN DAN SARAN}

Berdasarkan hasil penelitian yang telah diuraikan sebelumnya, maka dapat ditarik beberapa kesimpulan sebagai berikut : 1) Untuk nilai persamaan regresi didapat dari nilai $\mathrm{a}=47,509$ dan $\mathrm{b}=0,311$ mengganbarkan variabel gerak motorik kasar pada permainan lompat tali (X) memberikan pengaruh terhadap penurunan variabel prestasi lompat jauh (Y) satuan jenjang kriteria dan tanpa dipengaruhi faktor bebas apapun besarnya nilai gerak motorik kasar pada permainan lompat tali adalah 47,509 satuan jenjang kriteria. Hal ini ditunjukkan dengan persamaan regresi linier sederhana $\mathrm{Y}=47,509+0,311 \mathrm{X}$. , 2) Harga koefisien korelasinya sebesar 0,310 dan 
Shutan Arie Shandi : Analisis Gerak Motorik Kasar Pada Permainan Lompat Tali Terhadap Prestasi Siswa Putra Dalam Lompat Jauh Pada Kelas VIII SMP Negeri 2 Palibelo

$\mathrm{t}$-tebel sebesar 0,260, maka $\mathrm{t}$-hitung lebih besar dari t-tabel $(0,310>0,260)$ artinya ada pengaruh gerak motorik kasar pada permainan lompat tali terhadap prestasi siswa putra dalam lompat jauh pada kelas VIII SMP Negeri 2 Palibelo Kabupaten Bima.

\section{DAFTAR PUSTAKA}

Arikunto, Suharsimi, 1988. Prosedur Penelitian Suatu Pendekatan Praktis : Aneka Cipta Jakarta.

Ending, Ramadan BA, 1982. Pendidikan Olahragadan Kesehatan 2 : Angkasa Bandung.

Jess, Jerver, 1987. Belajardan Berlatih Atletik, Pioner Jaya Bandung.

Hadi, Sutrisno, 1984. Statistik Jilid 2 : Yogyakarta Fakultas Psikologi UGM.

Hadi, Sutrisno, 1995. Analisis Regresi Yogyakarta : Andi.

Harsono, 1988. Coaching dan Aspek - Aspek Psikologi Dalam Coaching : P2LPTK Jakarta.

HP, Suharno, 1985. Ilmu Kepelatihan Olahraga: Yogyakarta.

Kosasih. Engkos, 1985. Olahraga Teknikdan Program Latihan: Akadmika Presindo Jakarta. Riyadi, Tamsir, 1985. Petunjuk Atletik Yogyakarta : Dosen FPOK IKIP Yogyakarta.

Rusdyanto, 1988. Pembagian Kesegaran Jasmani Dengan Menggunakan Aerobik.

Said, Hasnan, 1977. Penilaian Kesegaran Jasmani ACRSPFT : Depdikbud Jakarta.

Sajoto, Mochammad, 1988. Pembina Kondisi Fisik Dalam Olahraga : Depdikbud Dikti Jakarta.

Suetejo, Pramoe, 1986. Diktat Atletik dan Pengetahuan Olahraga: Malang.

Suharsono, 1988. Choaching dan Aspek Psikologi : Depdikbud Dirjen Dikti Jakarta.

Sungkono, Bambang, Tahan, 1985. Statistik Sebagai Analisis Data Penelitian Anova Anarek, Anakova : FP MIPA IKIP Malang.

Sahadi, Answarudin, S.Pd, Cetakan II, 2011. Latihan Dasar Atletik: PT. Wadah Ilmu, Hak

Cipta @ Dilindungi Undang - Undang. 